\title{
Tensiones en torno al cuerpo, el género y el deseo en los Programas de estudio de educación para la afectividad y sexualidad integral de Costa Rica
}

Camilo Retana

Universidad de Costa Rica 


\title{
Tensiones en torno al cuerpo, el género y el deseo en los Programas de estudio de educación para la afectividad y sexualidad integral de Costa Rica*
}

\begin{abstract}
Resumen: el presente artículo se ocupa de analizar los Programas de estudio de educación para la afectividad y sexualidad integral del Ministerio de Educación Pública de Costa Rica (MEP). Para ello realiza una contextualización, en primer lugar, histórico-normativa y, en segundo lugar, política de dicha directriz educativa. Asimismo, el texto se interesa en estudiar el modo en que distintas agendas condicionan y tensan los contenidos de los Programas. Específicamente, el artículo se adentra en las concepciones del cuerpo, el género y el deseo de los Programas... para mostrar las visiones enfrentadas que implícitamente estructuran tales concepciones. El objetivo, así, es discutir críticamente la Educación Sexual en general, y los Programas de estudio de educación para la afectividad y sexualidad integral en particular, más allá de las posiciones dicotómicas (a favor-en contra) que suelen emplearse para tales efectos.
\end{abstract}

Palabras clave: educación sexual, cuerpo, género, deseo, Derechos Humanos, religión.

\section{Tensions around the body, gender and desire in the Educational study programs for affectivity and integral sexuality of Costa Rica}

\begin{abstract}
Educational study programs for affectivity and integral sexuality of the Ministry of Public Education of Costa Rica (MEP). For this purpose a contextualization of this education directive is made, firstly historical-normative and secondly political. Likewise, the text takes an interest in studying the mode in which different agendas condition and tense the contents of the Programs Specifically, the article deepens in the conceptions of the body, gender and desire of the Programs to demonstrate the confronted visions that implicitly structure such conceptions. The objective is to discuss critically Sexual Education in general, and Education Study Programs for the Affectivity and Integral Sexuality in particular, beyond the dihcotomic (in favor-against) that are usually utilized for these effects.
\end{abstract}

Keywords: sexual Education, body, gender, desire, Human Rights, religion.

Fecha de recepción: 27 de julio de 2018

Fecha de aceptación: 30 noviembre de 2018

Forma de citar (APA): Retana, C. (2019). Tensiones en torno al cuerpo, el género y el deseo en los Programas de estudio de educación para la afectividad y sexualidad integral de Costa Rica. Revista Filosofía UIS, 18(1), doi: http://dx.doi.org/10.18273/revfil.v18n1-2019006

Forma de citar (Harvard): Retana, C. (2019). Tensiones en torno al cuerpo, el género y el deseo en los Programas de estudio de educación para la afectividad y sexualidad integral de Costa Rica. Revista Filosofía UIS, 18(1), 129-150.

Camilo Retana: costarricense. Doctor en Filosofía. Profesor de la Universidad de Costa Rica.

Correo electrónico: camiloretana@gmail.com

ORCID: https://orcid.org/0000-0002-6442-7092

* Artículo de reflexión derivado de investigación. 


\section{Tensiones en torno al cuerpo, el género y el deseo en los Programas de estudio de educación para la afectividad y sexualidad integral de Costa Rica}

Los Programas de estudio de educación para la afectividad y sexualidad integral del Ministerio de Educación Pública de Costa Rica fueron aprobados en el año $2012^{1}$. Los Programas forman parte de una transformación curricular más abarcadora (véase la política curricular Educar para una nueva ciudadanía, aprobada por el Consejo Superior de Educación en acuerdo No. 07-64-2016), también impulsada por ese Ministerio, y recogen contenidos impartidos a lo largo de toda la primaria y de los primeros años de secundaria. En términos específicos, los Programas constituyen materiales didácticos dirigidos a docentes y su objetivo primordial es establecer pautas para la impartición, en décimo año, de la asignatura Educación para la Afectividad y Sexualidad Integral. Con ello, el MEP se propone garantizar:

el derecho efectivo de [los] estudiantes a una educación para la afectividad y sexualidad que sea integral, científica, contextualizada e inclusiva y que les permita desarrollar conocimientos, actitudes y habilidades para una vivencia plena y responsable de la sexualidad (MEP, 2017, p. 5).

A nivel de estructura, los Programas se dividen en un primer capítulo abocado a la fundamentación teórico-filosófica, un segundo dirigido a perfilar al estudiantado y el personal docente que se quieren promover hacia el futuro, un tercero que establece el diseño curricular al que obedecen las nuevas directrices, un cuarto capítulo que contiene el programa de estudios de la asignatura a impartir en décimo año y, por último, un glosario que dota de contenido teórico algunos de los conceptos empleados a lo largo del documento.

La coincidencia temporal entre el estreno de esa asignatura y las elecciones costarricenses del 2018, crispó los ánimos y polarizó la opinión pública básicamente en dos "bandos" ${ }^{\prime 2}$ por un lado, quienes estaban a favor de que se impartiera la asignatura y, por otro, quienes la rechazaban en nombre de la familia

${ }^{1}$ Para efectos de facilitación de la lectura, de ahora en adelante, se referirá las más de las veces el documento en cuestión como los Programas.

${ }^{2}$ Por supuesto, reducir la pluralidad de posturas y opiniones a dos polos equivale a incurrir en una simplificación imperdonable. La utilización provisional de esta dicotomía, en consecuencia, es meramente analítica y pretende delinear el panorama que acá nos ocupa antes que explicarlo a cabalidad. 
y los valores 3 . En términos generales, uno y otro "bando" se nucleó en torno a los partidos políticos que obtuvieron mayor cantidad de votos y que alcanzaron la segunda ronda: el oficialista Partido Acción Ciudadana (a la postre ganador de la elección) y el Partido Restauración Nacional.

Esta correspondencia entre una polarización con cariz sociocultural y una polarización de carácter partidario responde a la publicación de la Opinión consultiva OC-24/17 de la Corte Interamericana de Derechos Humanos. La sentencia ofrece respuesta a una solicitud realizada por el Estado costarricense el 24 de noviembre del 2017 y en ella se sienta jurisprudencia relacionada con la identidad de género y la discriminación contra parejas del mismo sexo. La opinión referida establece que el Estado costarricense debe garantizar el derecho al cambio de nombre y de género en los documentos de identidad, así como también proteger los derechos de las personas homosexuales a formar familias y a que estas sean protegidas del mismo modo que las conformadas por parejas heterosexuales (Corte Interamericana de Derechos Humanos, 2017, pp. 8788). Dado el talante progresista de la sentencia ${ }^{4}$ los sectores conservadores costarricenses, con el candidato presidencial evangélico Fabricio Alvarado del Partido Restauración Nacional a la cabeza, esgrimieron que la Corte atentaba contra la soberanía jurídica costarricense y amenazaron con retirar a Costa Rica del organismo internacional en cuestión si dicho partido ganaba las elecciones. Según palabras del entonces candidato presidencial,

Costa Rica es un país provida, profamilia, donde imperan valores judeocristianos y estoy seguro de que no tenemos nada que celebrar. No hay nada que acatar. [La resolución de la Corte Interamericana] no es vinculante y si fuera vinculante, un gobierno de Restauración estaría dispuesto a salirse de la Corte porque no estamos dispuestos a una agenda LGBTI, proaborto y una ideología de género (Chinchilla, 2018).

Adicionalmente, Fabricio Alvarado y los sectores que lo apoyaban aprovecharon para generar, a partir de dicha opinión consultiva, una equivalencia estratégica entre "ideología de género" y derechos de las personas LGTBI. De acuerdo con

\footnotetext{
${ }^{3}$ La evocación de la familia y los valores como argumentos para controlar la sexualidad no es nueva. La historiadora costarricense Carolina Quesada (2012) argumenta convincentemente que la injerencia de la religión en la historia de la política pública costarricense se encuentra empotrada en la invención misma de la nación costarricense.

${ }^{4}$ Progresismo designa, en el contexto de este artículo, una tesitura política de izquierda que se opone a cierto imaginario según el cual, dado que todo tiempo pasado fue mejor, la sociedad debe empeñarse en que las cosas jamás se modifiquen. Desde este punto de vista, tal como lo indica el filósofo argentino-costarricense Roberto Fragomeno, "lo progresista es un acompañante semántico de lo revolucionario [...]. El progreso hace progresar, sosteniendo la insatisfacción. Así, la idea de progreso no es un "ingrediente" u órgano de la modernidad, sino el indicador de su homesotasis general" (2018, p. 32).
} 
el plan de gobierno de Restauración Nacional, la agrupación encabezada por Fabricio Alvarado,

no podemos validar la ideología de género que los grupos LGTBI quieren promover, imponer y arraigar en la función pública y en la educación nacional del país. Para los restauradores es imposible aceptar que haya más de dos géneros, que estos estén divorciados del sexo al nacer, que estos se puedan intercambiar a gusto de las personas, que sustenten nuevas concepciones de matrimonio, que atenten contra la vida gestacional, que se escuden en la salud sexual y reproductiva para lograrlo y, entre otras muchas causales, que pasen de la búsqueda del respeto a la promoción de preferencias" (Alvarado, 2018, p. 48).

Como consecuencia de esta equivalencia estratégica trazada por Alvarado, la coyuntura electoral se planteó como una especie de referendo informal a propósito de los derechos de las personas LGTBI y la pertinencia de que se impartiera Educación Sexual en los colegios.

En el contexto de esta polarización político-electoral y de la novedad de que se impartieran los Programas por primera vez, se generó una persecución en contra de personas sexualmente diversas y se produjo un clima de abierta homofobia y misoginia. La configuración dicotómica del debate (se estaba o a favor o en contra de los Programas, lo cual equivalía a estar, a la vez, o a favor o en contra de los derechos de las personas LGTBI) provocó, por otra parte, que el contenido de los planes pasara a un segundo plano. De hecho, paradójicamente, el contenido de los planes nunca llegó a ser discutido públicamente, pues la agenda mediática se enfocó unilateralmente en ubicar a candidatos presidenciales, padres de familia y autoridades políticas (los estudiantes estuvieron sistemáticamente excluidos del debate) de un lado u otro de la dicotomía antes aludida, dejando de lado los contenidos y alcances de las reformas educativas impulsadas por el Ministerio.

En contra de esa inercia dicotómica, en este artículo interesa presentar algunos ejes de debate referidos a los Programas que, en el contexto surgido tras las últimas elecciones costarricenses, sería deseable retomar. En concreto, el presente texto se adentra en las tensiones conceptuales y presupuestos de los Programas a la hora de referir el cuerpo, el deseo y la sexualidad. Con ello, la intención es presentar los Programas a la manera de un índice (es decir, de un indicador, pero a la vez de un lugar de materialización y de disputa simbólica) de los debates en torno al lugar de la sexualidad en la vida cultural costarricense. Del mismo modo, importa mostrar que, en el caso de Costa Rica, más allá de la asunción de una postura dentro del binomio a favor-en contra de la Educación Sexual, es necesario realizar una lectura crítica que polemice la Educación Sexual en virtud de sus potenciales efectos coercitivos. 


\section{El contexto político de los Programas de estudio de educación para la efectividad y sexualidad integral del MEP}

La historia de la Educación Sexual en Costa Rica es la historia de una serie de pugnas, disputas y pulsos entre, por un lado, sectores clericales tradicionales, y por otro, movimientos sociales, actores políticos progresistas y una parte del gremio educativo (Fernández, 2010). Ninguno de esos "bandos", si es que cabe la expresión, es, sin embargo, del todo compacto. Carolina Quesada (2012), por ejemplo, argumenta que el movimiento obrero jugó un papel decisivo para que la Iglesia pudiese reclamar un lugar en el arbitrio de la vida sexual de la población costarricense. Dentro del ámbito religioso, asimismo, ha habido pronunciamientos a favor de los planes, como es el caso de la Iglesia Luterana ${ }^{5}$. También ha habido una parte del sector educativo que se ha pronunciado en contra de la Educación Sexual en los colegios.

Sin embargo, más allá de estas particularidades en la composición interna de los actores involucrados en estas disputas, lo cierto es que la posibilidad de integrar la Educación Sexual en los programas curriculares costarricenses se ha dado en el marco de una conflictividad social más amplia. Esto coincide con un panorama regional (piénsese en países como Brasil, Colombia, Perú, Guatemala o Nicaragua) en el que el tema de la Educación Sexual también opera como catalizador entre visiones de mundo enfrentadas en una amplia gama de temas, entre ellos el aborto, los métodos anticonceptivos, la violencia sexual, el lugar social de la familia y la diversidad sexual. En este escenario de enfrentamiento, los sectores socialmente progresistas en Costa Rica se han visto en la necesidad política de alinearse en torno a la defensa de los planes propuestos por el MEP, en la medida en que perciben en ellos una punta de lanza para posicionar temas en la agenda política, para tematizar luchas otrora invisibles y, sobre todo, para atender una serie de problemas sociales urgentes vinculados con el sexismo, la homofobia y la transfobia.

En el contexto anterior, como ya se ha dicho, los Programas del Ministerio de Educación Pública han tendido a ser examinados desde perspectivas reductivas que limitan a los interlocutores a decantarse a favor o en contra de la Educación Sexual pública. Así, frente a los ataques conservadores contra los Programas, el itinerario seguido por sectores feministas, LGTBI y por las universidades mismas, ha consistido en una defensa a ultranza (ciertamente comprensible desde un punto de vista coyuntural) de los nuevos planes educativos.

\footnotetext{
${ }_{5}^{5}$ José Manuel Morán (2018) señala los riesgos de reducir el activismo conservador en materia sexual a un activismo de tipo religioso. El problema con dicha reducción, señala Morán, es que no permite aprehender, en su complejidad heterogeneidad, la composición interna real de dichos movimientos y, por ende, tampoco permite descifrar su modus operandi.
} 
No obstante, quizá haya llegado el momento de preguntar qué es lo que estos sectores han venido defendiendo con tanto ahínco. Por otro lado, también cabe preguntar hasta qué punto la filosofía de la sexualidad que subyace a las políticas actuales del MEP resulta políticamente satisfactoria para dichos sectores. Esta toma de distancia crítica con los Programas de estudio de educación para la afectividad y sexualidad integral no se traduce, por cierto, en una alineación con los sectores que se han decantado en contra de las prerrogativas del Ministerio. Por el contrario, es probable que salir de una perspectiva dicotómica permita una reflexión más profunda acerca del lenguaje, la retórica política y los instrumentos jurídicos y analíticos empleados en las luchas sexuales actuales.

La intención acá, por ende, no es someter los Programas del MEP a examen para medir su grado de radicalidad, ni tampoco dictaminar si se trata de buenos o malos instrumentos. Por lo demás, ningún programa es en sí mismo garantía de éxito o fracaso, dado que es en su implementación donde se dirime el tipo de impacto que una política educativa dada puede llegar a tener ${ }^{6}$. En cambio, lo que sí se desea enfatizar en el contexto de este escrito es el hecho de que, después de todo, en su génesis, pero también en su despliegue, la Educación Sexual emerge del mismo pliegue discursivo que las epistemes higienistas, normalizadoras y medicalizantes (Béjin, 1987) tan certeramente criticadas por los propios movimientos feministas, queer y LGTBI, así como por los autores y autoras de esos mismos movimientos. A saber: si bien la Educación Sexual posee una utilidad política en la medida en que garantiza derechos y augura justicia y protección a actores sociales de otro modo desprotegidos, también es cierto que se trata de un dispositivo de control social de la sexualidad, tal y como se desprende de la crítica foucaultiana plasmada en La voluntad de saber (Foucault, 2005, pp. 40-41)7. En este sentido, cabe también puntualizar el hecho de que el rechazo de los Programas por parte de los sectores

${ }^{6}$ El asunto de la implementación de los Programas excede los límites del presente escrito. A propósito de algunos de los desafíos que puede llegar a comportar dicha implementación puede verse León et al. (2013). Daniel Fernández (2017) también rastrea, aunque con mucha mayor solvencia analítica y consistencia teórica, algunas de las preconcepciones y prejuicios relacionados con la sexualidad que suelen circular en el ámbito educativo costarricense y que, sin duda, dibujan un panorama poco halagüeño para la implementación de cualquier política educativa progresista en esa materia.

${ }^{7}$ A propósito de las limitaciones y eventuales alcances emancipatorios de las políticas institucionales en materia sexual, me permito referir al lector o lectora al esclarecedor texto de Kathya Araujo Entre el paradigma libertario y el paradigma de derechos: límites en el debate sobre sexualidades en América Latina. Tal y como lo anticipa el título de su artículo, Araujo distingue entre un "paradigma de los derechos" y un "paradigma libertario". En su opinión, se trata de matrices epistemológico-políticas que se decantan por opciones hasta cierto punto inversas. Mientras que en el "paradigma de derechos" se apuesta por regular estatalmente la sexualidad en virtud de su inscripción dentro de campos de poder, en el segundo se opta por una liberalización de la sexualidad más escéptica respecto de los efectos emancipadores de los aparatos jurídicos. En términos de Educación Sexual, el "paradigma de derechos" considera el tutelaje estatal como un elemento necesario más allá de sus consecuencias a nivel de control social, debido a que pone coto a distintas formas de violencia relacionadas con la sexualidad. Según el "paradigma libertario", en cambio, la Educación Sexual participa de un conjunto de mecanismos de control estatal que excluyen y castigan las sexualidades disidentes. El presente artículo se inscribe fundamentalmente dentro de esta segunda tradición. 
más conservadores de la sociedad costarricense es en realidad circunstancial, en el sentido de que hace parte de una agenda más ambiciosa que bien podría optar en el futuro por una reforma de los planes en clave tradicionalista si es que ello resultara más estratégico. Dicho de otro modo, no debería confundirse el árbol con el bosque: los Programas del MEP tienen una valía coyuntural, pero al mismo tiempo hacen parte, no sin cierta ambigüedad, de un paisaje político-cultural más amplio en el que se juega el control social de la sexualidad. De ahí la necesidad de superar las visiones dicotómicas que reducen el debate en torno a la Educación Sexual a una lógica de sí o no.

\section{Los entresijos intertextuales de los Programas de estudio de educación para la afectividad y sexualidad integral del MEP}

En su propia estructura retórico-discursiva, los Programas de estudio para la afectividad y sexualidad del MEP informan de una cierta conflictividad social en torno a la sexualidad. En su desarrollo, los Programas establecen una serie de diálogos intertextuales (los cuales serán caracterizados en breve) con discursos acerca de la sexualidad, y libra con ellos una especie de pulso. Al ritmo de ese pulso el texto retrocede, introduce matices, realiza concesiones a posiciones en pugna, se inscribe en tradiciones discursivas a veces incompatibles y se ubica en medio de unos antagonistas imaginarios que, a menudo, estructuran y tensionan el contenido del documento. En breve: los Programas se saben parte de un contexto social escindido en torno al rol cultural de la sexualidad y el placer.

De manera esquemática, y en función de trazar una cartografía de los entresijos intertextuales que estructuran los Programas, es posible distinguir cuatro interlocuciones ramales que atraviesan los mismos. Con este mapeo, la intención es mostrar cómo la reforma curricular planteada por el MEP se encuentra acosada por varias agendas políticas que entienden la sexualidad de modos distintos y que reclaman, cada una por su lado, incidencia en las políticas públicas.

Un primer intertexto presente en los Programas remite al universo jurídico y, más concretamente, a los instrumentos de Derechos Humanos. Según el documento: "la vivencia de la sexualidad desde un enfoque de Derechos Humanos busca fortalecer la noción de sujetos de derechos y responsabilidades, reconociendo que es derecho de todas las personas vivir una sexualidad segura, informada, corresponsable, placentera y saludable" (MEP, 2017, p. 5). Esta apelación al discurso de Derechos Humanos opera a lo largo del documento, a la vez, a la manera de una fuente de legitimación y de coerción. En otras palabras, los Programas... apelan a una discursividad jurídica que se advierte prácticamente incontrovertible dentro del imaginario social, pues nadie afirma al menos no pública ni frontalmente- estar en contra de los Derechos Humanos. No debería olvidarse, sin embargo, que, en materia de sexualidad, a menudo 
el "derecho se erige [...] como una arena de disputas [...] pero también como un discurso instrumentalizado mediante el cual se pueden regular los cuerpos" (Morán, 2018, p. 13). Así, tras esa apelación, se encuentra implícita una elección ético-epistemológica anterior: la inscripción de la sexualidad dentro de matrices filosóficas universalistas y humanistas, con todo y los potenciales efectos de normalización presentes en ellas. En esta línea, el documento refiere, por ejemplo, que "los Derechos sexuales y Derechos reproductivos [guardan] relación con los valores éticos universales" (MEP, 2017, p. 21), con lo cual los Programas se blindan contra posicionamientos refractarios a las políticas igualitaristas, al tiempo que postulan un humanismo universalista eventualmente excluyente. El universalismo como matriz filosófica y los Derechos Humanos como matriz jurídica custodian, así, las políticas del MEP en contra de la crítica a unos ciertos mínimos éticojurídicos que, de lo contrario, quedarían expuestos al cuestionamiento por parte de visiones conservadores.

En segundo término, los Programas establecen un diálogo, a veces velado y otras veces más bien explícito, con sectores religiosos. Ya sea que se invoque la espiritualidad como imbricada fundamentalmente con la sexualidad (2017, p. 15), o que se vea en esta última un fenómeno con cariz religioso, es claro que el documento reconoce en la autoridad religiosa a un interlocutor. Así, según el documento, "la sexualidad es el resultado de la interacción de factores biológico, psicológicos, socioeconómicos, culturales, éticos y religiosos o espirituales" (2017, p. 8). Respecto de esta interlocución con actores religiosos cabe señalar que los Programas eligen un posicionamiento más bien concesivo (se ofrecerán ejemplos de esas concesiones en apartados posteriores). La consigna, pareciera, es no suscitar escándalo innecesariamente entre esos grupos. En consecuencia, el documento establece un compromiso tácito con ellos al no sustraer del todo el aura espiritualista con que las religiones han rodeado históricamente la sexualidad.

Esto entra en contradicción directa con un tercer discurso que nutre ideológicamente los Programas, a saber: el discurso científico. A menudo, en efecto, se evoca la ciencia como fundamento epistemológico de los planes, con lo cual el enfoque religioso queda puesto en entredicho. De este modo, los Programas refieren continuamente la necesidad de proveer una "información amplia, objetiva y científica" (MEP, 2017, p. 11) que colisiona con el espiritualismo propio de los discursos religiosos presentes en el documento. Aun cuando, más adelante, se estudiarán acá con cierto nivel de detalle los efectos que esa evocación de lo científico posee en el texto, por ahora interesa señalar el hecho de que tal fundamentación es reivindicada no sin cierto pudor positivista. La ciencia, en efecto, aparece como fuente de evidencia incontrovertible (MEP, 2017, p. 18), como elemento objetivador de la experiencia sexual y como discurso que compele al acatamiento obligatorio. 
Por último, existe un diálogo subterráneo en los Programas en relación con los enfoques que analizan la sexualidad en términos de su despliegue históricosocial. A partir de una serie de referencias, algunas veces veladas pero otras veces explícitas, el texto ve en la sexualidad un fenómeno sociohistóricamente moldeado y propenso a la reconfiguración, a la aculturación y al influjo del poder, y refiere la importancia de visibilizar los "movimientos sociales que se han desarrollado en Costa Rica, a lo largo de la historia, para la defensa de los derechos sexuales" (MEP, 2017 , p. 52). En tal sentido, el documento ofrece noticia sobre la importancia de las luchas libradas por el feminismo y los movimientos LGTBI, al tiempo que hace mención de la posibilidad, para algunos cuerpos, de sufrir "sanciones sociales" (39) cuando no coinciden con las normas hegemónicas.

De este modo, mientras los Derechos Humanos fungen en el texto como fundamento jurídico y los discursos científicos como fundamento epistemológico, las explicaciones sociohistóricas de la sexualidad aparecen en pugna con los encuadres religiosos por ver cuál proporciona el marco ético más adecuado para la vivencia de la sexualidad.

Las complejas interacciones entre esas cuatro matrices marcan el tono de cuanto los Programas dicen. El documento propuesto por el MEP se quiere un instrumento pedagógico capaz de atender algunos de los problemas sociales relacionados con la sexualidad adolescente, pero con la difícil tarea de satisfacer, en el medio, preceptos religiosos, postulados científicos, exigencias jurídicas de organismos internacionales y reivindicaciones políticas de movimientos sociales. Es verdad que hay algo en ello de voluntad conciliatoria y de vocación sincera al diálogo. También es cierto que, dependiendo de cómo se tomen, esas matrices no siempre entran en contradicción. Pero es igualmente cierto que podría verse en tal empresa un intento condenado al fracaso de concertar posiciones que, fuera del documento, a menudo antagonizan abiertamente. Dicho en lenguaje coloquial, todo ocurre como si los Programas apuntaran a "quedar bien con Dios y con el Diablo".

Como sea, hay que reconocer que la confección e implementación de los Programas... constituye una demostración sociológica del impacto que los sectores progresistas — provengan estos de los movimientos feministas, queer, LGTBI o del ámbito universitario - han tenido en el imaginario social y la agenda política costarricense. En otras palabras, el hecho de que un programa educativo del gobierno haya de intentar equilibrar sus puntos de vista ponderando la reacción y posición de los movimientos sociales relacionados con la sexualidad, sea que estos apelen a un discurso de corte más jurídico o que sostengan posiciones más radicales, da cuenta del hecho de que se ha abierto una herida en el seno de la moral conservadora costarricense. El rol del Estado en ello, por cierto, no ha sido menor, en la medida en que ha reconocido la legitimidad de ciertas reivindicaciones impulsadas por movimientos feministas y LGTBI, cosa que no 
necesariamente ha ocurrido a lo largo del orbe ni tampoco en la mayoría de países de nuestra región.

Esto no impide, sin embargo, que los Programas promovidos por el MEP contengan una serie de postulados, posiciones y perspectivas que reclaman revisión. De hecho, desde una perspectiva crítico-filosófico, cabe someter a cuestionamiento no únicamente la naturalización de la sexualidad por vía religiosa, sino también la normalización de la sexualidad que, por vía científica, e incluso jurídica, opera en algunos fragmentos de los Programas.

En adelante, me centraré en mostrar de qué manera subyacen a los Programas algunos de esos núcleos conceptuales discutibles desde una política sexual progresista. En concreto, me centraré en presentar críticas puntuales a las nociones de cuerpo, género y deseo de los Programas, con el objetivo de mostrar ciertas tensiones conceptuales y consecuencias normativas que se desprenden de las políticas educativas del MEP.

\section{Del cuerpo de los Programas a la programación de los cuerpos}

La irrupción del cuerpo en los Programas es señal de una voluntad de sustraer la sexualidad de cierto ámbito metafísico en el que esta suele estar inscrita en la mayoría de los discursos conservadores. A saber: si la sexualidad suele remitirse a conceptos trascendentales (v. gr. "la persona" o "los valores") como parte de una estrategia de des-incardinación, la referencia al cuerpo devuelve a la sexualidad su dimensión eminentemente material. Sin embargo, esa ruptura con las perspectivas metafísicas es en los Programas, desde un principio, vacilante. Según el documento del MEP, en efecto, "la sexualidad no se desarrolla en abstracto y no se refiere solamente a la dimensión emocional y espiritual [sino que] se expresa en el cuerpo y a través de él, aunque también lo trasciende" (MEP, 2017, pp. 2526). Dentro de esta perspectiva, la sexualidad ocurre en el cuerpo y, por tanto, constituye un fenómeno físico, pero, al mismo tiempo, se trata de un fenómeno que excede ese cuerpo. En otras palabras, el cuerpo opera como la instancia en la que la sexualidad tiene lugar, pero la esencia de esta última se juega en otra parte, en la medida en que "las corporalidades, [...] trascienden lo meramente físico y biológico" (MEP, 2017, p. 26). Este mismo desdoblamiento es detectable en la dicotomía que opone el cuerpo a la corporalidad. Según reza el documento del MEP:

la corporalidad hace referencia a la vivencia subjetiva del cuerpo, la cual comprende los afectos y vínculos, el placer, las identidades y diversidades, la salud, el bienestar, la cultura, el poder y la violencia. Se trata de un cuerpo cargado de representaciones sociales y culturales así como de un cuerpo sujeto de derechos (2017, p. 61). 
De forma distinta a la corporalidad, el cuerpo de los Programas remite, así, a una "realidad objetiva" (MEP, 2017, p. 26), regida ya no por lo simbólico ni por la percepción, sino por las leyes anatómicas. En torno a lo corpóreo existiría, pues, un plano subjetivo, conformado por la corporalidad, las vivencias, los afectos y la cultura, y un plano objetivo, en el que el cuerpo no conoce de aculturación ni es susceptible de modificaciones, porque está-ya-ahí.

Estos desdoblamientos, ya sea entre cuerpo y corporalidad, ya sea entre cuerpo y espiritualidad, tienen, como se sabe, un largo abolengo dentro de la filosofía y la teología occidentales. En efecto, toda una tradición platónicacristiana enarbola la separación del espíritu y el cuerpo, como un modo de tutelar la vida de este último. Posteriormente, de la mano del cartesianismo, acaece toda una reformulación moderna de este modelo dualista. Por supuesto, este no es el lugar apropiado para enumerar cada una de las consecuencias políticamente indeseables que este dualismo occidental ha acarreado para el cuerpo. No obstante, con ocasión de su presencia en los Programas, quizá sí sea pertinente recordar la gran cantidad de relaciones de poder que dicho dualismo ha propiciado en el campo de la sexualidad. Me refiero al hecho de que, mediante una serie de estrategias discursivas e institucionales, el dualismo ha sido empleado históricamente para subordinar la somaticidad, para abstraer la sexualidad de las condiciones materiales de existencia y para imponer preceptos morales (tal es el caso, por ejemplo, de las argumentaciones dualistas empleadas en la prohibición del aborto, de las políticas dualistas de la Iglesia Católica dirigidas al control de la sexualidad de los feligreses, o de la utilización política del dualismo para prohibir la fecundación in vitro, por mencionar solo algunos ejemplos).

Por otra parte, resulta igualmente pertinente recordar el modo en que dicho dualismo ha sido sometido a interrogación en reiteradas ocasiones por movimientos feministas y LGTBI, así como también por diversos autores y autoras de dichos movimientos. Para el feminismo de Luce Irigaray (1978), por ejemplo, el dualismo se encuentra no solo en el centro de los mecanismos de poder occidentales, sino que opera al interior de toda la metafísica occidental, orientando y estructurando los modelos epistemológicos y ontológicos socialmente dominantes. Desde un punto de vista queer, asimismo, los dualismos no solo resultan tributarios de filosofías de la sexualidad típicamente conservadoras, sino que además resultan centrales en los proyectos de esencialización de los sujetos. En este sentido, estos enfoques enfatizan el modo en que, a través del dualismo, el cuerpo es sujetado a partir de una esencia que se supone que lo antecede, y que desconoce la dimensión performativa de la existencia encarnada (Butler, 2007). En otras palabras, el dualismo resulta un enclave fundamental para el gobierno de los cuerpos, por cuanto establece una serie de normas de subjetivación a partir de las cuales se exige al cuerpo ajustes y se reclama a los sujetos adherencia a arquetipos identitarios. 
El problema, sin embargo, no es únicamente la apelación de los Programas a visiones dualistas ancladas en visiones metafísico-religiosas de la afectividad y la sexualidad. Antes bien, ocurre que a partir de ese dualismo el cuerpo, escindido de la esfera más "aculturable" de la corporalidad, encuentra su propio régimen de control. En otras palabras, el desdoblamiento de la sexualidad en una dimensión espiritual-subjetiva y otra carnal-objetiva, no solo abre las puertas a una eventual educación religiosa de la dimensión supuestamente inmaterial de la sexualidad, sino que, a la vez, crea las condiciones para que, en su dimensión "objetiva" y carnal, el cuerpo quede confinado a un control biopolítico ejercido en nombre de la ciencia.

De hecho, en los Programas la sexualidad se encuentra inscrita en un régimen de verdad signado por los discursos medicalizantes que la circunscriben al ámbito de la salud. Para Morán, se trata de una situación generalizada en la región, toda vez que

de uno u otro modo, los argumentos basados en el pecado, la animación del cuerpo o los dogmas eclesiales, son reemplazados por discusiones sobre el rol de las hormonas, las neuronas y los genes. La ciencia, como discurso de poder, [resulta de esta manera] motorizada como espacio de construcción de una verdad en torno al cuerpo, en resistencia a los nuevos paradigmas sexuales" (Morán, 2018, p. 112).

La presencia de tal tipo de procedimiento resulta particularmente notorio en uno de los ejercicios planteados en los Programas En él se propone que los y las estudiantes distribuyan la información que poseen sobre la sexualidad en torno a dos columnas: la de los "mitos" referidos al placer y el sexo, y la de las "verdades" relacionadas con estos. Como es previsible, tras el ejercicio, la persona docente debe encargarse "de que quede suficientemente claro cuáles son los mitos y cuál es la información correcta que los aclarara" (MEP, 2017, p. 32). El ejercicio, sin duda, pone en marcha lo que Foucault denominó el "beneficio del locutor", en la medida que otorga potestad al profesor de catalogar los conocimientos previos de sus estudiantes como mitológicos o verdaderos según unos criterios de validez preestablecidos $^{8}$. El documento, de hecho, resume el rol del docente en el aula señalando que, en el ejercicio, "la persona facilitadora retoma lo producido por el grupo y realiza un aporte científico" (p. 18). En otras palabras, en el entramado de saber-poder dispuesto por los Programas, el conocimiento sobre la sexualidad se construye colectivamente, pero en el entendido de que dicho conocimiento debe ajustarse a unos estándares epistémicos preestablecidos, dispuestos por el Ministerio en la figura del profesor.

${ }^{8}$ El "beneficio del locutor" constituye una estratagema retórica que tiene lugar en torno al sexo. En esta estratagema, el locutor reniega de la represión y con ello se rodea de un aura transgresora. No obstante, mientras simula hablar desde fuera del poder, enuncia unas supuestas verdades sobre el sexo que, a la postre, plantea como de acatamiento obligatorio. Véase (Foucault, 2005, p. 13). 
Empero, más que realizar una crítica al dispositivo pedagógico propuesto en los Programas, lo que se desea ejemplificar acá es el modo en que la dimensión objetiva del cuerpo es postulada como una manera de incrustar la sexualidad en el ámbito biopolítico del saber biomédico ${ }^{9}$. En dicho ámbito, la ciencia se erige como criterio de verdad y, por lo tanto, como límite infranqueable para la deconstrucción ${ }^{10}$. El resultado general de esta dicotomía cuerpo-corporalidad o, si se prefiere, cuerpo-espiritualidad produce, así, una escisión entre una esfera simbólica peligrosamente propensa al adiestramiento espiritual de un lado, y un cuerpo objetivo propenso al control biopolítico del otro.

El asunto no se resuelve, sin embargo, con una simple reivindicación monista frente al dualismo de los Programas, ni tampoco sustrayendo — si es que tal cosa fuera posible, o si quiera deseable - los contenidos científicos de los mismos; tampoco se agota substituyendo una epistemología de la sexualidad "incorrecta" por otra "correcta", pues ello simplemente nos desplazaría de un régimen de verdad a otro. Más bien, el señalamiento central que acá se desea realizar es que la pragmática del documento del MEP postula una corporeidad desdoblada en la que lo somático queda regulado mediante aparatos de control de la carne, de forma complementaria al modo en que la consciencia queda aún en los dominios de los antiguos dispositivos de control de las almas. Todo ocurre como si, al margen del cuerpo, o al lado de él, el discurso religioso acosara a los Programas, demandando el reconocimiento de una esfera espiritual que debe ser postulada para que el documento sea admisible. Así, del cuerpo de los Programas se termina desprendiendo una política de programación de los cuerpos en la que prima la vieja scientia sexualis descrita por Foucault, pero en contubernio con las lógicas religiosas de control de la sexualidad por vía del alma.

\section{Diversidad sexo-genérica y políticas de la identidad}

Los Programas de estudio de educación para la afectividad y sexualidad integral realizan, alrededor de la noción de género, un auténtico esfuerzo por implementar algunos de los aportes epistemológicos formulados por el feminismo y la teoría queer $^{11}$. En el documento, el género remite a una serie de construcciones y

\footnotetext{
${ }^{9}$ Sobre el modo en que el cuerpo sexuado ingresa al ámbito biopolítico de los cálculos y la gubernamentalidad estatal en Occidente a través discursos sanitarios, véase el análisis foucaultiano -ya hoy clásico - desarrollado en la parte final de La voluntad de saber.

${ }^{10}$ Para una discusión pormenorizada acerca del modo en que se han establecido históricamente límites a la deconstructibilidad del cuerpo sexuado. Véase (Butler, 2008, pp. 53-94).

${ }^{11}$ En su glosario, por ejemplo, el documento incorporaba inicialmente nociones de una enorme radicalidad crítica, como por ejemplo el concepto de "heteronormatividad". Se trata, en este caso puntual, de un constructo de incuestionables alcances emancipadores, en virtud de su acento en la dimensión irreductiblemente sociocultural de la sexualidad. Sin embargo, la noción fue sustraída de los Programas como resultado de una negociación política sobre la cual se volverá al final del presente texto.
} 
significados elaborados culturalmente, con lo cual las diferencias biológicas no agotan las posibilidades de los cuerpos generizados sino que, más bien, los abren a distintas posibilidades más allá de la dicotomía hombre-mujer. En otras palabras, los Programas establecen la posibilidad de una Educación Sexual no binaria, en la que los significados y la autopercepción del cuerpo no encuentran su límite último e irreductible en la anatomía.

No obstante, este enfoque entra en contradicción con cierta naturalización de los sexos que también recorre el documento. Acá, de nuevo, la adscripción al discurso cientificista, y más específicamente biologicista, impone un límite a una política del género más radical ${ }^{12}$. Mientras que, a partir del discurso sobre diversidad se plantea un "paradigma [que] pretende trascender la dualidad normalanormal [y] comprender que todas las expresiones son válidas" (MEP, 2017, p. 63), la invocación de los Programas a la "salud sexual" (9) defiende, de forma no exenta de contradicciones, un paradigma sanitario adscrito a biopolíticas naturalizadoras del sexo ${ }^{13}$. De este modo, aun cuando, en el marco del documento, "salud" remita a un estado no restringido a la ausencia de enfermedad y ligado a la posibilidad de desarrollo personal y social, lo cierto es que la citación de dicho concepto trae consigo toda una estela semántica con derivas medicalizadoras y naturalizantes del sexo.

De hecho, la apelación de los Programas a un sexo medicalizado tiene, de nuevo, el efecto de incrustar la Educación Sexual en un régimen de verdad científico que le proporciona legitimidad social. Así, cuando los Programas proceden a disertar a propósito del lugar de la naturaleza respecto al sexo, señalan que este último:

\footnotetext{
12 Es verdad que no toda visión científica en lo general, ni biológica en lo particular, participa necesariamente de políticas naturalizantes del sexo. De hecho, distintas autoras al interior del feminismo y la teoría queer han reivindicado visiones científicas y biológicas con vocación antinaturalizante (piénsese en los aportes pioneros de autoras como Fausto-Sterling o Donna Haraway). En el caso de los Programas, sin embargo, los discursos científicos operan más bien imponiendo un límite a la deconstrucción de los sexos, tal y como mostraré en breve.

${ }^{13}$ Las sociedades normalizadoras aparecen conceptualmente empotradas, tal y como sabemos a partir de los trabajos de Foucault, en la dicotomía normalidad/patología. Dicha dicotomía, a su vez, aparece en el seno de las sociedades modernas de la mano de una episteme médica que, desde muy temprano, otorgó connotaciones morales a lo patológico. Esquemáticamente, las sociedades normalizadoras tienen, así, su génesis en la patologización de la enfermedad y en la superposición discursiva del mal, lo anormal y la enfermedad. El castigo a las desviaciones de las normas encuentra, en esta misma medida, su justificación epistémica en las visiones naturalizadoras-sanitarias de los sexos.

Por supuesto, como cualquier otro concepto, la noción de "salud" admite resemantización. No obstante, en el caso de los Programas, no basta con acometer tal resemantización: sería asimismo necesario dar cuenta de cómo conviven, en un mismo marco, éticas jurídicas normalizadoras de la sexualidad y éticas libertarias de la diversidad sexual (aún cuando el asunto no pase simplemente por decantarse dogmáticamente por uno u otro modelo ético). De nuevo el texto de Araujo y su distinción entre el "paradigma libertario" y el "paradigma de derechos" resulta en este punto crucial, en la medida en que, en un plano más general, da con el nudo central del dilema que acá se intenta plantear, a saber, el hecho de que "en América Latina, la coexistencia muchas veces inadvertida de estas posiciones [...] deja sin percibir y recoger un abanico significativo de problemas y preguntas" (2008, p. 31).
} 
corresponde a características biológicas (genéticas, endocrinas y anatómicas) que usualmente son utilizadas para agrupar a los seres humanos como miembros de un grupo masculino o femenino. Si bien es cierto estos conjuntos de características biológicas no son mutuamente excluyentes, pues existen diferentes grados en la forma en que se manifiestan, en la práctica han sido utilizados para establecer una diferenciación dentro de un sistema binario (hombre-mujer; macho-hembra) (MEP, 2017, p. 68).

A partir de este enfoque, el sexo responde a una dimensión biológica que admite solo de forma muy ambigua interpretación y adaptación socioculturales. A saber: el sexo posee en los Programas una constitución binaria inherente, cuya deconstrucción solo es posible, temporal y ontológicamente, en la instancia posterior y degradada de la significación; la sexualidad, así, "forma parte de la naturaleza humana y [...] constituye una dimensión intrínseca a la existencia de la persona" (MEP, 2017, p. 7; énfasis propio). Según esta óptica, en síntesis, la distancia con el binarismo solo puede ser relativa, toda vez que el sexo se encuentra natural y ontológicamente configurado en virtud de una constitución intrínseca del cuerpo (64).

Evidentemente, la tensión entre naturalismo y constructivismo es compleja y difícilmente resoluble en un documento institucional con las características de los Programas. No obstante, lo que se desea enfatizar acá es cómo estas tensiones entre constructivismo y naturalismo responden a agendas encontradas que el documento procura, no sin cierto malabarismo retórico, poner a funcionar en paralelo.

Ello ocurre también en lo tocante al posicionamiento del documento del MEP respecto de las actuales polémicas relacionadas con la noción de identidad. Como se sabe, mientras que las primeras teorizaciones feministas encontraron su fundamento en la defensa y reivindicación de la identidad femenina, las elaboraciones feministas y queer contemporáneas han señalado una serie de limitaciones de ese enfoque ${ }^{14}$. Tanto en la teoría como en la práctica de los actuales movimientos feministas y LGTBI, la identidad se revela como un constructo engañoso que, al tiempo que permite reivindicar una serie de derechos, petrifica formas subjetivas en realidad móviles, inacabadas o en curso. De este modo, las políticas de la identidad, si bien útiles en términos de la consecución de derechos, resultan hasta cierto punto esencilizadoras del sexo.

En los Programas (aun cuando hay que decir que se trata de una limitación que excede el marco de la Educación Sexual costarricense), el lugar de estas antiguas políticas de la identidad resulta, una vez más, ambiguo. Por un lado, la adscripción del enfoque jurídico de Derechos Humanos sintoniza con las políticas

\footnotetext{
${ }^{14}$ Para una pormenorizada y completa crónica de los desplazamientos feministas con respecto a la noción de identidad, véase María Luisa Femenías, Sobre sujeto y género (2012).
} 
esencializantes del sexo, pero por otro, la apelación a visiones radicalmente construccionistas comulga con visiones de corte postidentitario. El texto, empero, no apunta a conjugar ambas visiones ni a ponerlas en relación. Antes bien, el documento apela por igual a la idea de que el género es una expresión de una identidad sexual ya dada, como a la idea de que la identidad constituye un constructo resultante de prácticas negativas de discriminación. Puede que esa doble apelación no resulte en sí misma escandalosa, e inclusive que llegue a tener algún rédito estratégico, pero ocurre que en los Programas no media proceso analítico alguno de puesta en relación entre dos agendas que, fuera de la política educativa del MEP son, hasta cierto punto, antagonistas. Así, el documento se encuentra una vez más tensado por distintas visiones políticas que, pese a que se advierten contradictorias, se intentan mantener en una convivencia no reflexionada. El resultado es de una tensa coexistencia entre matrices cuyos alcances progresistas se encuentran a menudo revocados por visiones más afines a los imaginarios sexuales de corte conservador.

\section{El deseo como promesa de autorrealización}

En ningún caso los alcances limitados de los Programas se revelan con mayor fuerza que en lo tocante a su utilización del concepto de deseo. Si bien los Programas no entran a definir explícitamente ese concepto (la noción, de hecho, no tiene su entrada en el glosario que figura al final del documento, como sí ocurre en el caso de otras categorías), a lo largo del texto se encuentra implícita una visión del deseo en el que este se liga a la autorrealización del yo y a la consecución de la plenitud psicológica. Esta visión es deudora, a la vez, de una concepción de la subjetividad que atraviesa todo el proyecto pedagógico de los Programas. En otras palabras, mediante el imaginario sobre el deseo articulado en los Programas es dable rastrear el paradigma subjetivo que pretenden impulsar las reformas educativas del MEP en materia sexual.

Pero ien qué consiste dicho paradigma?, ¿de qué modo aparece el deseo como elemento institucional y, más en concreto, estatalmente programable? La parte inicial del documento del MEP resulta crucial para responder estas preguntas. En ella se establece el racionalismo como basamento filosófico de las reformas educativas a impulsar en materia de sexualidad $y$, de la mano de ese basamento, se plantea toda una antropología filosófica y un proyecto de pedagogía. El racionalismo, tal y como lo entienden los Programas a partir de la Política educativa hacia el siglo XXI del Consejo Superior de Educación,

reconoce al ser humano como un ser dotado de una capacidad racional que le permite "captar objetivamente la realidad en todas sus formas, construir y perfeccionar de continuo los saberes y hacer posible el progreso humano, el entendimiento en las personas" (Consejo Superior de Educación, 1994, p. 6) (sic) (MEP, 2017, p. 13). 
Esta visión de lo humano, por lo demás típicamente ilustrada, postula un tipo de subjetividad en la que el deseo difícilmente encuentra lugar. Al suscribir una antropología filosófica prototípicamente moderna en la que el sujeto se define primordialmente por sus cualidades racionales, el deseo queda postulado como una cualidad por educar. Freud (1927) sometió tempranamente esta comprensión del deseo a una severa crítica en la medida de su omisión del carácter eminentemente negativo o destructivo del deseo. En efecto, aún cuando el psiquiatra vienés comulgó con la deseabilidad de someter el deseo a cierto nivel de contención para garantizar la sostenibilidad de la cultura, su postura es que la libido posee una faceta irreductiblemente destructiva que no admite una pedagogización completa. En una palabra: ya el propio psicoanálisis había interrogado el optimismo antropológico de la Ilustración señalando su olvido de la pulsión de muerte. Así, a partir de las elaboraciones del psicoanálisis, pero también de otras corrientes posteriores como la genealogía nietzscheana, la imagen moderna de un sujeto cuyos deseos se encuentran recortados a la medida de su razón ha venido siendo sistemáticamente criticada por su falta de reconocimiento de la dimensión negativa o destructiva del placer y el inconsciente.

Las reelaboraciones queer de estas críticas freudianas enfatizan, por su parte, el modo en que tal dibujo ilustrado de la economía libidinal de los sujetos ofrece réditos a la hora de programar la sexualidad. Guy Hocquenghuem (2009), por ejemplo, plantea a partir de su lectura crítica de Freud que la educabilidad del deseo genera las condiciones de posibilidad para su heterosexualización. En una lectura de mayor afinidad para con el psicoanálisis, Leo Bersani (2011) encuentra en el placer sexual un elemento generador de crítica, precisamente por cuanto acarrea consigo una deconstrucción de lo que creemos saber del yo. Lee Edelman (2004), por último, postula, en la misma línea de Bersani, la pulsión de muerte como locus de resistencia queer en contra de los esfuerzos culturales por contener el inconsciente y organizarlo para garantizar la "viabilidad de lo social" (20). En todos estos planteamientos queer se rechaza la programación del deseo en nombre de una negatividad crítica que reniega de las visiones ilustradas, en virtud del hecho de que, en ellas, la libido se presenta unilateralmente como un capital por ser administrado.

Volviendo a los Programas, la postulación de un sujeto primordialmente racional redunda en una visión del deseo prefreudiana (y en consecuencia prequeer) en la que la libido posee una misión edificadora, cosa que se advierte ya en la conexión establecida en el título del documento entre sexualidad, afectividad e integralidad. La vivencia de la sexualidad, según esta perspectiva, "garantiza bienestar y desarrollo para las personas, $y$, por ende, para las familias, las comunidades y las sociedades en general" (MEP, 2017, p. 26). Educar la sexualidad es, así, educar al ciudadano para que construya una sociedad mejor, aún cuando no está claro en qué consiste tal sociedad, o si consiste en lo mismo para todos y 
todas. Ocurre, sin embargo, que la libido posee, según lo argumentan las teorías del deseo antes referidas, una faceta negativa que riñe con esta visión. La opacidad del deseo defendida tanto por el psicoanálisis como por la teoría y el activismo queer — opacidad ligada directamente a sus posibilidades de insubordinaciónresulta, así, borrada de un plumazo en los Programas, en nombre de un enfoque prístino y puro del deseo en el que la vivencia de la sexualidad se torna una suerte de obligación cívica. En una palabra, toda aquella pulsión sexual que no resulte socialmente constructiva desde el punto de vista del optimismo ilustrado, resulta de una peligrosidad que exige pedagogización.

Esta visión abiertamente normalizante de la sexualidad (cuyo apotegma pareciera ser que solo es válida la sexualidad que contribuye a la sociedad, cualquier cosa que eso signifique) entronca, además, con la visión sanitaria del sexo a la que he hecho referencia antes en varias ocasiones. A partir de este entronque, la sexualidad de los Programas se revela como ámbito decisivo en el despliegue de dispositivos biopolíticos ligados a la gestión de la salud, el control de la reproducción y la medicalización del sexo. En concordancia con el régimen discursivo instaurado por la scientia sexualis, el placer se torna, de este modo, blanco epistemológico de discursos abocados a "conocer las verdades del placer" (MEP, 2017, p. 32). Esta inscripción del deseo en el campo de la salud y en el régimen de verdad que le es concomitante, suprime, a la vez, la posibilidad de un "erotismo descentrado", abierto a la resignificación performativa15. Dicho de otro modo, el placer y el erotismo se presentan en los Programas como fuente por antonomasia de autorrealización y completud, y con ello se allana el camino para hacer de la programación del deseo un bien incuestionable (toda vez que se trata de un derecho). El deseo, postulado como telos del sexo, queda así entrampado en un régimen obligatorio que no admite resignificación.

Esta esencialización del deseo, no obstante, riñe una vez más con la veta progresista de los Programas. Tal parece, en efecto, que la reivindicación de la diversidad, la crítica de la exclusión y la denuncia de la violencia sexual encuentran en esta visión normativa del deseo su límite, pues más allá de esta vivencia del placer como fuente de realización plena no pareciera haber sexualidad pensable. De este modo, si las políticas inclusivas y los discursos de Derechos Humanos tienen en la equidad y el igualitarismo su punto de partida, le pregunta sigue siendo qué ocurre cuando aparecen sexualidades y deseos que no se corresponden con

\footnotetext{
15 Por "erotismo descentrado" me refiero a un cierto tipo de ética sexual que no se somete a una verdad fija, sino que se plantea como un conjunto de prácticas provisorias, ciertamente relacionadas con normas y criterios de verdad, pero cuyo énfasis se encuentra puesto en lo que Foucault llamaría los "modos de sujeción" a esas normas, y no tanto en las normas en sí. El "erotismo descentrado" privilegia, en consecuencia, el desplazamiento, la ironía y la crítica de unas "verdades" que, aún siendo vinculantes para los sujetos, no determinan su vivencia del placer. Desde esta perspectiva, las normas sexuales son de todos modos mutables, en razón del efecto trastocador de las adhesiones variopintas que los sujetos realizan a ellas.
} 
nuestra imagen previa de lo igual, y que se anclan, por el contrario, en la diferencia y la negatividad radicales.

\section{La resolución práctica de las tensiones: Ia influencia conservadora en la implementación de los Programas}

A manera de recapitulación, cabe señalar que, tal y como ocurre con distintas políticas públicas, los Programas de estudio de educación para la afectividad y sexualidad integral del Ministerio de Educación Pública de Costa Rica están atravesados por pugnas sociales que los preceden y estructuran. En el caso específico de esta disposición educativa, diversas visiones sobre la sexualidad - o más concretamente sobre el cuerpo, el género y el deseo- pugnan en direcciones contrarias. Al interior de los Programas existe un esfuerzo por conciliar esas posiciones encontradas (o a veces confrontadas). Sin embargo, esos esfuerzos conciliatorios no resuelven, y posiblemente no pueden resolver, los conflictos sociales que los han suscitado en primer término.

De hecho, a partir de las disputas de la coyuntura electoral aludida al inicio de este texto, algunas de las tensiones conceptuales internas a los Programas fueron resueltas fuera de los mismos. A saber: como resultado de una negociación entre el partido ganador de las elecciones (en la figura de su candidato electo Carlos Alvarado) y el Partido Unidad Social Cristiana, algunos contenidos de los Programas fueron suspendidos. Más específicamente, el glosario que figuraba al final de los Programas como material de apoyo para los docentes, y una de las actividades propuestas para la asignatura de décimo año, fueron retirados a partir de la solicitud del ex candidato Rodolfo Piza ${ }^{16}$. Tanto la actividad como el glosario contenían algunas de las posiciones más sugerentes en términos de una política sexual radical, en cuenta la defensa de una sexualidad no biologicista y el perfilamiento de conceptos desanturalizadores de la homosexualidad y el binarismo de género. En otras palabras, las tensiones conceptuales que he marcado en las páginas precedentes se han resuelto, de momento, a partir de un cálculo político-electoral, en favor de las posiciones más conservadoras del espectro político costarricense. Esa concesión supone un decidido retroceso en la agenda de los movimientos feministas y LGTBI más radicales.

En resumen, el panorama que se abre a partir del análisis precedente deja ver que, en materia sexual, los sectores conservadores costarricenses no se van a contentar con posiciones conciliatorias, sino que intentarán imponer su agenda. En razón de ello, los sectores progresistas debemos hacer otro tanto y abocarnos

\footnotetext{
${ }^{16}$ En realidad, más que una solicitud, se trataba de una condición de cara a la segunda ronda electoral: si el entonces candidato - y hoy presidente - Carlos Alvarado accedía a la petición de Piza, este, a su vez, accedería a conformar una alianza electoral. Alvarado, a la postre, acabó consintiendo la solicitud y la alianza firmada por ambos partidos ganó la elección. Hoy Piza es el Ministro de la Presidencia de la gestión Alvarado.
} 
decididamente a posicionar nuestra propia agenda, pues más allá de la dicotomía chantajista a favor-en contra de los Programas, lo cierto es que las luchas políticosexuales no se agotan en la aprobación o el rechazo de una política educativa.

\section{Referencias}

Alvarado, F. (2018). Plan de Gobierno 2018-2022 por Restauración Nacional. Recuperado de http://www.tse.go.cr/dondevotarp/partidos/ programasPoliticos/2018/33_108820284.pdf

Araujo, K. (2008). Entre el paradigma libertario y el paradigma de derechos: límite en el debate sobre sexualidades en América Latina. En K. Araujo y M. Prieto. (Eds.), Estudios sobre sexualidades en América Latina (pp. 25-42). Quito: FLACSO.

Béjin, A. (1987). El poder de los sexólogos. En P. Ariès; A. Béjin y M. Foucault. (Comps.), Sexualidades occidentales (pp. 249-282). Barcelona: Paidós.

Bersani, L. (2011). El cuerpo freudiano: psicoanálisis y arte. Buenos Aires: El cuenco de plata.

Butler, J. (2007). El género en disputa. El feminismo y la subversión de la identidad. Barcelona: Paidós.

Butler, J. (2008). Cuerpos que importan: sobre los límites materiales y discursivos del sexo. Barcelona. Paidós.

Chinchilla, S. (20 de febrero de 2018). Fabricio Alvarado: 'Nunca dije que fuera la primera opción' salirse de la Convención de Derechos Humanos. La Nación. Recuperado de https://www.nacion.com/el-pais/politica/fabricio-alvarado-nuncadije-que-fuera-la/DF2U2CNKSFFWPKB6TNQKZ23PL4/story/

Corte Interamericana de Derechos Humanos (24 de noviembre de 2017). Opinión consultiva OC-24/17. Recuperado de http://www.corteidh.or.cr/docs/opiniones/ seriea_24_esp.pdf

Edelman, L. (2004). No al futuro. Barcelona-Madrid: Egales.

Femenías, M. L. (2012). Sobre sujeto y género. Rosario: Prohistoria.

Fernández, A. (2010). Influencia de la Iglesia Católica en la construcción de representaciones sociales sobre sexualidad. Un análisis de la Política de Educación de la Expresión de la Sexualidad Humana Del Ministerio de Educación, 2000-2009 (Tesis de maestría inédita). Universidad de Costa Rica, San José, Costa Rica. 
Fernández, D. (2017). Corporalidades disidentes. En T. Cordero (Comp.), Reflexiones desde la investigación socio-educativa en contextos de exclusión (pp. 87-110). San José: Instituto de Investigaciones en Educación.

Foucault, M. (2005). La voluntad de saber. Ciudad de México: Siglo XXI.

Fragomeno, R. (2018). Las palabras intermitentes: progreso, nación y utopía. San José: Arlekín.

Freud, S. (1927-1996). El porvenir de una ilusión. En Obras Completas (Tomo $\mathrm{XXI}$. Buenos Aires: Amorrortu.

Hocquenghem, G. (2009). El deseo homosexual. Madrid: Merlusina.

Irigaray, L. (1978). Speculum. Espéculo de la otra mujer. Madrid: Saltés.

Ministerio de Educación Pública de Costa Rica (2015). Educar para una nueva ciudadanía. Recuperado de http://www.idp.mep.go.cr/sites/all/files/idp_mep_go_ cr/publicaciones/7-2016_educar_para_una_nueva_ciudadaniafinal.pdf

Ministerio de Educación Pública de Costa Rica (2017). Programas de estudio de educación para la afectividad y sexualidad integral. Recuperado de http://www.mep. go.cr/sites/default/files/programadeestudio/programas/afectividadsexualidaddiversificada.pdf

Morán, J. M. (2018). Religión, secularidad y activismo heteropatriarcal: iqué sabemos del activismo opositor a los Derechos Sexuales y Reproductivos en Latinoamérica? Revista de Estudios de género La Ventana, 47, 97-138.

León, G. et al. (2013). Percepción de una muestra de educandos y docentes sobre la implementación del Programa educación para la afectividad y sexualidad integral. Revista Electrónica Educare, 17, 145-165.

Quesada, C. (2012). Familia y heteronormatividad: acontecimientos históricos y la doctrina sexual de la Iglesia Católica en Costa Rica. Anuario de Estudios Centroamericanos, 38, 305-328. 